\title{
ANÁLISE AMBIENTAL E OCUPACIONAL DA ÁREA DE PRESERVAÇÃO PERMANENTE - APP DO PERÍMETRO URBANO DA CIDADE DE JABOTICABAL, S.P.
}

Renata Cristina Araújo Costa

Teresa Cristina Tarlê Pissarra

Flávia Mazzar Rodrigues

Anildo Monteiro Caldas

Sergio Campos

Beatriz Oliveira Costa

RESUMO: Dentro do contexto de uso e ocupação do solo e desenvolvimento da sociedade, a análise da ocupação de área de preservação - APP - merece destaque para auxiliar na elaboração de projetos ambientais a serem realizados e conduzidos pelo poder público. Os principais objetivos deste projeto foram analisar e discutir o uso e ocupação das APPs no perímetro urbano de Jaboticabal, relatar a importância destas áreas florestais em áreas urbanas, e delimitar as áreas de APP passíveis de recuperação. Para tanto, utilizou-se de técnicas de análise visual de imagens orbitais de alta resolução e visitas nas áreas de estudo. Os resultados mostram que a APP urbana de Jaboticabal possui um alto nível de adequação ambiental, visto que a maior área não está ocupada por imóveis ou pavimentação urbana.

Palavras chave: Área verde. Bacia hidrográfica. Uso e ocupação do solo. 


\section{INTRODUÇÃO}

Segundo Cruz (2003), a bacia hidrográfica é uma área geográfica natural formada por uma área da superfície terrestre, que contribui na formação e no armazenamento de um determinado curso d'água, sendo delimitada pelos pontos mais altos do relevo (espigões, divisores de água). É considerada como unidade territorial de trabalho para fins de manejo e conservação do solo e da água, por ser um sistema aberto no qual as ações que ocorrem na superfície refletem principalmente no recurso hídrico (PISSARRA, 2002).

O manejo integrado em microbacia hidrográfica implementa uma nova maneira de se planejar e utilizar os recursos naturais, indo de encontro ao desenvolvimento sustentável (ROCHA e KURTZ, 2001). Para a implantação dessa proposta é necessário o conhecimento do meio físico, a partir das características morfométricas (diagnóstico físico) e de sua aplicabilidade, tanto na abordagem linear como adimensional, a qual traz informações relevantes na relação solo-superfície.

Devido ao desmatamento das florestas, desde 1965 as margens dos recursos hídricos foram protegidas por lei. No ano, entrou em vigor o Código Florestal Brasileiro, que teve como objetivo proteger além dos recursos hídricos a fauna e a flora nativa.

Associado aos estudos sobre dinâmica de uso do solo na bacia de drenagem e tendo em vista que os rios são denominados de ecossistemas incompletos, pois são dependentes do ecossistema terrestre, este trabalho terá como objetivo analisar e discutir o uso e ocupação das áreas de APP na bacia hidrográfica, do perímetro urbano de Jaboticabal, relatar a importância dessas áreas florestais em áreas urbanas; e delimitar as áreas de APP passíveis de recuperação e adequação ambiental.

\section{MATERIAL E MÉTODOS}

\section{Área de estudo}


O Município de Jaboticabal está localizado na parte Centro-Norte do Estado de São Paulo, província geomorfológica do Planalto Ocidental Paulista, cujo relevo predominante é suavemente ondulado com altitude média de $600 \mathrm{~m}$, situado em um dos pontos que tem como coordenadas geográficas latitude $21^{\circ} 15^{\prime} 22^{\prime \prime}$ e longitude 48 18' 58" próximo às Cuestas Basálticas que limitam este Planalto com a Depressão Periférica da Bacia do Paraná.

Segundo a distribuição territorial datada de 1-VII- 1960, o município é constituído por 3 distritos: Jaboticabal, Córrego Rico e Lusitânia. O distrito contemplado pela pesquisa será exclusivamente 0 de Jaboticabal por apresentar maior área e desenvolvimento socioeconômico, e uma população de 71.662 habitantes. (IBGE, 2010).

A área encontra-se dentro do Bioma do cerrado, porém a região recebe interferências da mata atlântica com sua Floresta Estacional Semidecidual por estar na zona de transição (IBGE, 2012). O clima da região é Aw segundo a classificação climática de Koeppen. Essa região apresenta um clima tropical com estação chuvosa no verão e estação seca no inverno (CEPAGRI, 2012).

Os córregos analisados pertencem à Bacia Hidrográfica do Mogi Mirrim, Microbacia do Córrego Rico. O estudo foi realizado no perímetro urbano de Jaboticabal, nos dois córregos Jaboticabal e Cerradinho. O mapeamento foi realizado no programa AutoCAD 2008, tendo como referências as Cartas do IBGE (1971), escala 1:50.000 e as imagens do satélite WordView (1:30) de 2010. A vetorização da imagem levou em consideração somente a área de preservação permanente - APP - prevista por lei, 30 metros de cada margem, para determinação das classes de uso e ocupação do solo.

\section{Uso e ocupação do solo das APPs}

As imagens e cartas planialtimétricas foram inseridas em arquivos do software na sequência do menu de opções no programa AutoCad. Com o uso da ferramenta polyline, foi realizada a adequação do limite da microbacia da carta cartográfica em comparação à imagem de satélite. Para a determinação das áreas de APP foi utilizado a operação offset, 
12.651, de 25 de maio de 2012, que altera o código florestal e dispõe sobre a proteção da vegetação nativa, como uma área protegida coberta ou não por vegetação nativa, com a função ambiental de preservar os recursos hídricos, a paisagem, a estabilidade geológica, a biodiversidade, o fluxo gênico de fauna e flora, proteger o solo e assegurar o bem-estar das populações humanas.

Atualmente os municípios estão buscando se adequar ao ideal de sustentabilidade e vários incentivos estão sendo feitos, principalmente no Estado de São Paulo, no qual foi criado o Projeto Município Verde Azul, com o objetivo de avaliar as áreas de preservação permanente e conservar esses locais, tendo em vista que, no passado não foram respeitados pela lógica imobiliária e por atividades antrópicas (SMA, 2008).

$\mathrm{Na}$ maioria das cidades brasileiras, as margens dos rios estão complemente degradadas, e a maioria das áreas ao longo da rede de drenagem se encontra canalizada ou rodeada por casas ou depara-se com áreas impermeabilizadas, como calçadas e ruas.

De acordo com a legislação ambiental brasileira, segundo a Lei no 4.771, de 15 de setembro de 1965 (Código Florestal) e a Resolução n 303, de 20 de Março de 2002, CONAMA, Art. $3^{\circ}$, as áreas de preservação são definidas e consideradas em áreas urbanas consolidadas. O Plano Diretor da cidade de Jaboticabal, em sua seção XI, na qual é tratado o planejamento rural e urbano, no seu Art. 35. §2º, III- prevê que a Administração Municipal procurará avaliar e desocupar as áreas de preservação permanente e inundável, ao longo dos Córregos Jaboticabal, Hospício, do Asilo e Córrego Rico e áreas de Ocupação.

A partir da leitura da legislação ambiental e análise da área situada ao longo da rede de drenagem foi realizado um diagnóstico dessas áreas para fins de planejamento urbano. A princípio foi realizada uma análise criteriosa da legislação pertinente. Entre as leis analisadas pode-se citar:

- LEGISLAÇÃO E ACORDOS INTERNACIONAIS:

- Agenda 21

- LEGISLAÇÃO FEDERAL: 
- Lei № 12.651, de 25 de maio de 2012. - Dispõe sobre a proteção da vegetação nativa;

- Lei N 6.938, de 31 de agosto de 1981 - Política Nacional do Meio Ambiente;

- Lei no 9605/1998 - Lei dos Crimes Ambientais;

- Lei 4771, de 15 de setembro de 1965 - Código Florestal;

- Lei no 7.754, de 14 de abril de 1989 - Proteção das florestas existentes nas nascentes dos rios;

- Resolução n. 303, de 20 de março de 2002. Dispõe sobre parâmetros, definições e limites de Áreas de Preservação Permanente.

- LEGISLAÇÃO ESTADUAL:

- Lei no 9509/1997 - Política Estadual do Meio Ambiente.

- LEGISLAÇÃO MUNICIPAL:

- Constituição Municipal de 1990 - Lei Orgânica do Município de Jaboticabal;

- Lei Complementar Municipal n 80, de 09 de outubro de 2006 - Plano Diretor de Desenvolvimento de Jaboticabal;

- Lei no 2820, de 13 de abril de 2000 - Disciplina o corte e poda de árvores no Município de Jaboticabal.

Após o levantamento da legislação, foram realizadas visitas técnicas em torno das margens dos córregos urbanos para verificar a real situação dessas áreas. Além da análise in loco foi realizado uma análise visual em imagens orbitais no intuito de verificar se a área total de APP, neste caso 30 metros ao longo da rede de drenagem (córregos de até $10 \mathrm{~m}$ de largura) estava sendo respeitada, de acordo com a legislação.

\section{Estudo de Caso: município de Jaboticabal}

A determinação dos layers de usos e ocupações partiu da necessidade de se determinar as interferências antrópicas existentes nas Áreas de Preservação Permanente (APP) nos córregos Jaboticabal e Cerradinho.

$\mathrm{Na}$ Figura 1, observa-se a área da Microbacia do Córrego do Jaboticabal representada pela linha roxa, e em verde estão delimitadas as APPs de todos os 


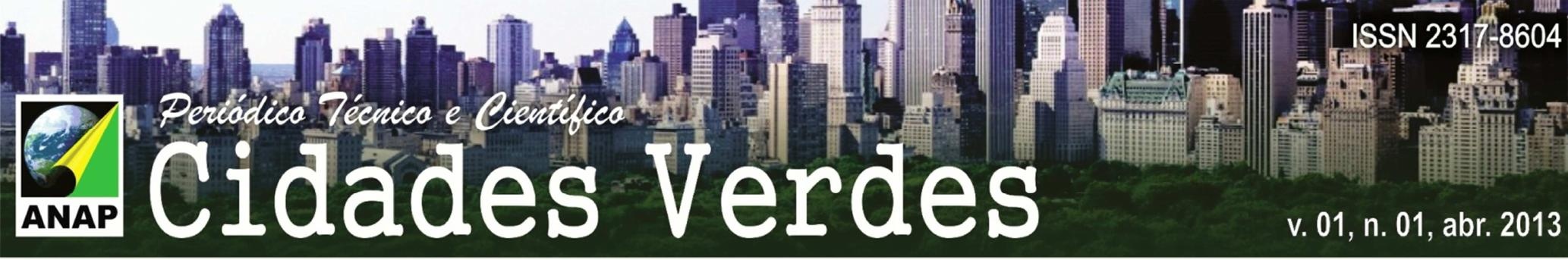

Tabela 1: Microbacia do Córrego do Jaboticabal.

\begin{tabular}{c|cc}
\hline & Área $\left(\boldsymbol{m}^{2}\right)$ & $\%$ \\
\hline Área Total Microbacia & $84.923 .022,76$ & 100 \\
Perímetro urbano vetorizado & 20470862 & 24,1 \\
Área Total APP urbana & 661868139 & 3,2 \\
\hline
\end{tabular}

Foram determinados 4 usos, a partir da análise visual da imagem orbital. São elas caracterizadas por: Vegetação, Campo sujo, Área impermeável, Área edificada, como podemos visualizar na Figura 2. As áreas de cada polígono foram calculadas pelo programa AutoCAD e depois armazenadas em uma planilha no Excel.

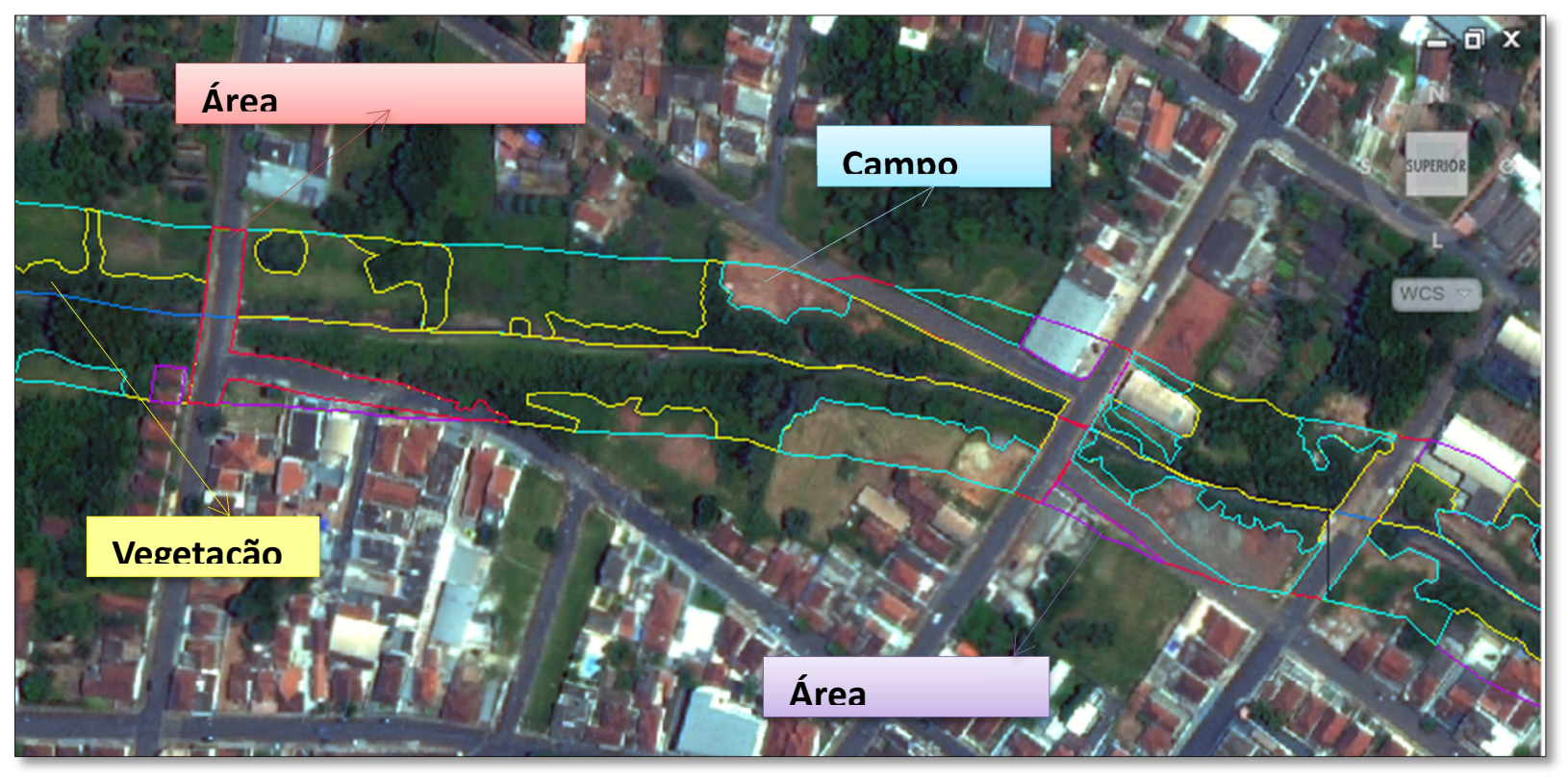

Figura 2: Mapa de uso e ocupação da APP do Córrego do Jaboticabal.

Após a determinação das áreas de cada uso e ocupação, as áreas foram somadas no próprio Excel e apresentada pela Tabela 2. O procedimento foi realizado para todo o perímetro urbano e os resultados são apresentados primeiramente em usos do solo nas APPs do perímetro urbano. Em seguida, foi realizada uma análise e discussão da realidade de cada córrego. 
Na Tabela 2 abaixo, pode-se analisar o uso e ocupação do solo da APP urbana da cidade de Jaboticabal.

TABELA 2: Classes de uso da terra mapeadas na imagem do Satélite World View na microbacia hidrográfica da área urbana da cidade de Jaboticabal.

\begin{tabular}{c|cc}
\hline Classes de uso e ocupação & Área ${\left(\boldsymbol{m}^{2}\right)}$ & $\%$ \\
\hline Vegetal & $199.307,371$ & 30,1 \\
Campo Sujo & 275580,923 & 41,6 \\
Áreas Edificadas & 69435,287 & 10,5 \\
Área Impermeabilizada & $117.544,558$ & 17,8 \\
\hline Total & $661.868,139$ & 100,0 \\
\hline
\end{tabular}

Pode-se observar a partir dos dados coletados que a cidade de Jaboticabal apresenta uma boa capacidade de adequação das suas APPs, denominadas de "Campo Sujo" segundo dados da vetorização; 41,6\% (Tabela 2) das áreas não possuem ocupação, assim é possível elaborar um planejamento para reflorestamentos urbanos. Estas áreas, por não estarem ocupadas por imóveis são passíveis de realização de tal obra, pois conforme Lei no 11.977 de 7 julho de 2009, não configuram áreas que necessitam de regulação fundiária. Segundo a mesma lei, as APPs ocupadas depois de 31 de dezembro de 2007 podem sofrer processos de regulação fundiária das APPs (BRASIL, 2009).

A adequação ambiental das áreas não edificadas "Campo Sujo" deverá ser realizada de forma que depois de um tempo não seja abandonada pelo órgão público e/ou vandalizada pela população local. Uma forma de isso não acontecer é o aproveitamento dessas áreas para a construção de áreas de convívio social, como é o caso dos parques Lineares, que segundo Oliveira e Borges (2011) propiciam uma apropriação pela população local, que passa a utilizá-las como áreas de lazer e esporte, contribuindo para a manutenção das obras realizadas no local (OLIVEIRA e BORGES, 2011; AMORIM e CORDEIRO, 2003). Segundo Oliveira e Borges (2011), esse tipo de parque vem sendo especialmente utilizado para o uso de áreas protegidas, como é o caso das APPs, pois este tipo de obra de acordo com estudos realizados por Friedrich (2007) apud Oliveira e 


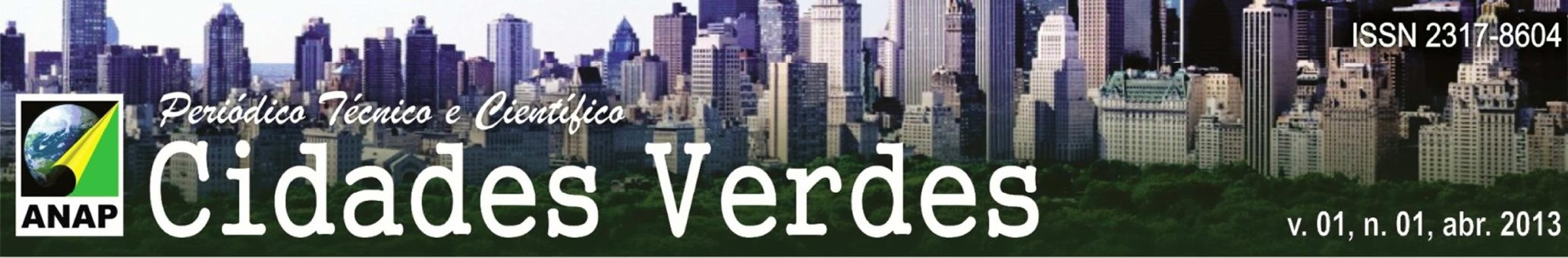

Borges (2011), apresentam baixo impacto ambiental e de enorme ganho social, visto que nestes empreendimentos podem ser instalados equipamentos culturais, esportivos, recreativos, de lazer, educativos ou para prática de caminhadas, que não necessariamente necessitam da impermeabilização do solo e/ou supressão da vegetação arbórea existente.

\section{Realidade do Córrego do Jaboticabal}

Após análise de forma geral das APPs da cidade de Jaboticabal, foi realizado um estudo na área de ocupação de cada córrego. A discussão será realizada na área ao longo do Córrego do Jaboticabal, desde sua nascente até a foz no córrego do Cerradinho quanto ao uso e ocupação do solo, áreas passíveis de reflorestamento e as interferências antrópicas observadas no seu curso, como obras de canalização e processos erosivos.

$\mathrm{Na}$ Figura 3, os polígonos realizados em todos os usos e ocupação são observados a partir da análise visual da imagem de satélite, do Córrego do Jaboticabal. Os totais das áreas de cada uso podem ser encontrados na Tabela 3.

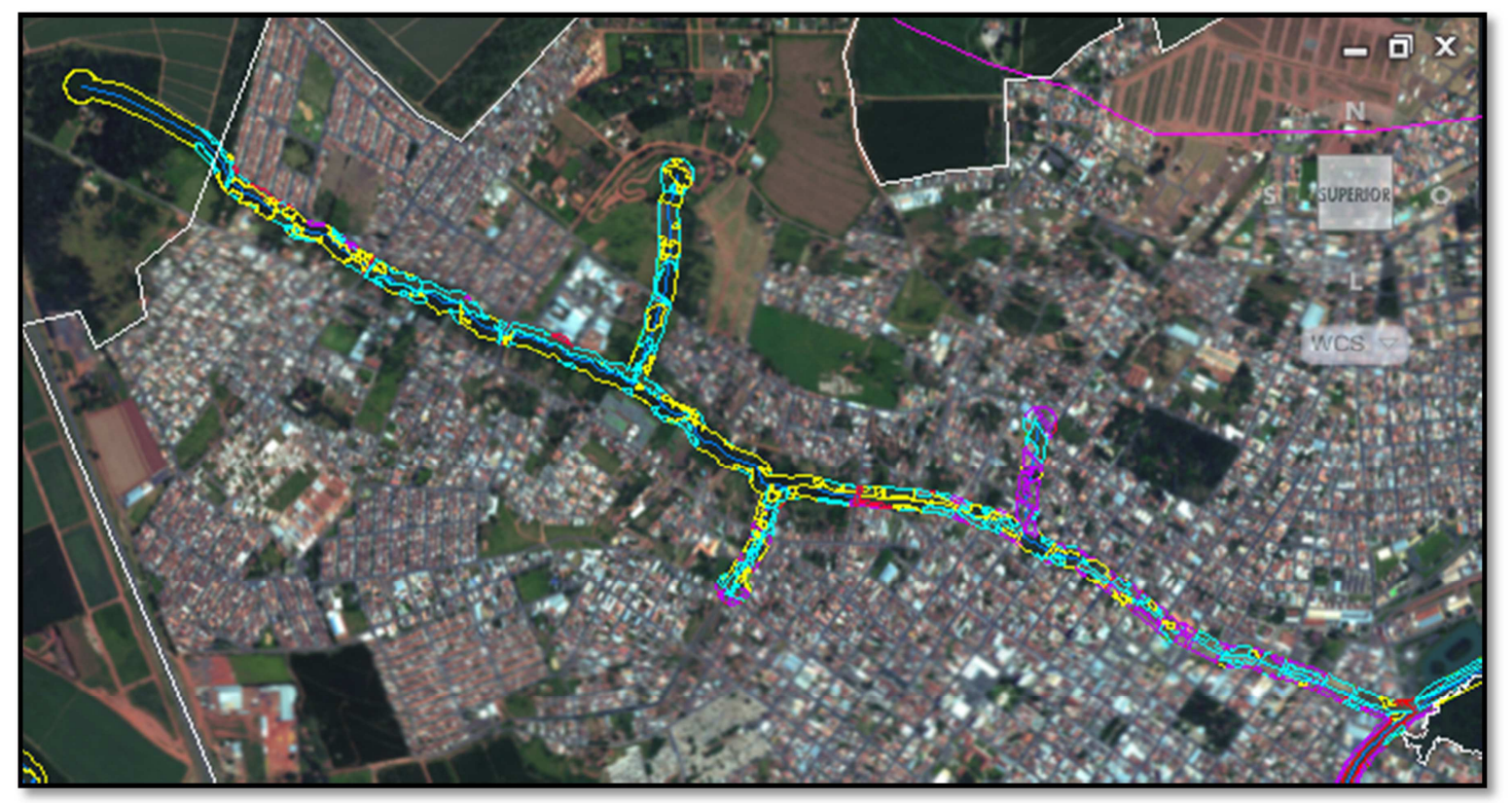

Figura 3: APP vetorizada do Córrego Jaboticabal. 
Como podemos observar na Tabela 3 abaixo, a maior superfície de APP, em área urbana, não está coberta por vegetação, porém neste caso um percentual considerável é de fragmento florestal comparado aos outros usos (47,6\%). Essas áreas encontram-se, principalmente, em bairros distantes do centro da cidade e no centro da cidade predomina o uso com edificações e áreas impermeáveis.

Outro dado importante é que existem algumas áreas que podem ser reflorestadas, possibilitando um ganho social ou econômico. São áreas de "Campo Sujo", chegando a um total de 34,2\% (Tabela 3). Desta forma, podem-se colocar essas áreas como superfícies passíveis de reflorestamento.

TABELA 3: Classes de uso da terra mapeadas na imagem do Satélite World View na microbacia hidrográfica do Córrego do Jaboticabal.

\begin{tabular}{c|cc}
\hline Classes de uso e ocupação & Área ${\left(\boldsymbol{m}^{2}\right)}$ & $\%$ \\
\hline Vegetal & $170.536,76$ & 47,6 \\
Campo Sujo & $122.826,23$ & 34,2 \\
Áreas Edificadas & $41.421,01$ & 11,6 \\
Área Impermeabilizada & $23.754,21$ & 6,6 \\
\hline Total & $358.538,21$ & 100,0 \\
\hline
\end{tabular}

As áreas com maior dificuldade para desenvolver ações que respeitem a legislação, seriam as em que existem algum tipo de ocupação, representada pelos usos de "Área edificada" (casas, lojas, indústrias etc.) e "Áreas Impermeabilizadas" (qualquer tipo de pavimentação urbana: ruas e calçadas), que somando totalizam 18,2\% (Tabela 3).

Das áreas com vegetação, muitas estão com sérios problemas de origem antrópica, como podemos observar na Figura 4. O córrego do Jaboticabal enfrenta diversos problemas no seu afloramento. A nascente se encontra canalizada e seu afloramento se encontra na periferia da cidade, onde problemas de destinação correta dos resíduos sólidos e educação ambiental ainda são precários. 

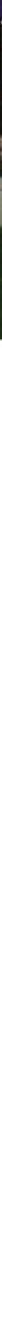

Figura 4: Córrego do Jaboticabal, Ponte da Av. Jacomo Bertioli. Acervo pessoal, 2012.

Neste trecho, mostrado na Figura 4, o córrego recebe uma enorme quantidade de resíduos sólidos (sacolas plásticas, pneus, garrafas pet) classificados como de origem doméstica. Esse evento acontece principalmente próximos às ruas, pontes, dentro e fora do córrego. 

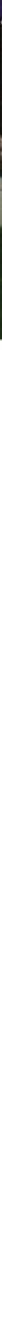

Figura 5. Processo Erosivo do lado da canalização do Córrego do Jaboticabal. Acervo pessoal, 2012.

Esse tipo de poluição e processos de erosão contribui para o aumento da quantidade de sólidos totais que alteram a qualidade da água. De acordo com Amorim e Cordeiro, (2003) deve-se respeitar o afastamento mínimo estabelecido pela legislação vigente para ocupação de suas margens, visando evitar problemas como este observado na Figura 5, onde a impermeabilização do solo pode intensificar processos erosivos urbanos. De acordo com Moraes et al. (2009) para evitar esse tipo de erosão é necessário manter grandes extensões sobre o leito maior do córrego. Esse procedimento auxilia que as águas das chuvas se dissipem em sua energia e se infiltrarem.

Para Tucci (2008), a densificação urbana proporciona um aumento na quantidade de resíduos sólidos. Já os processos de erosão mais intensificados acontecem em áreas com inicio de urbanização (Figura 5), onde é retirada a vegetação que protege as margens e impermeabilização. Os depósitos de resíduos sólidos acabam por gerar fonte contínua de contaminação das águas superficiais e reprodução de vetores de algumas doenças como a Dengue, o mosquito Aedes aegypti (TUCCI, 2008; SANTOS, 1998) 

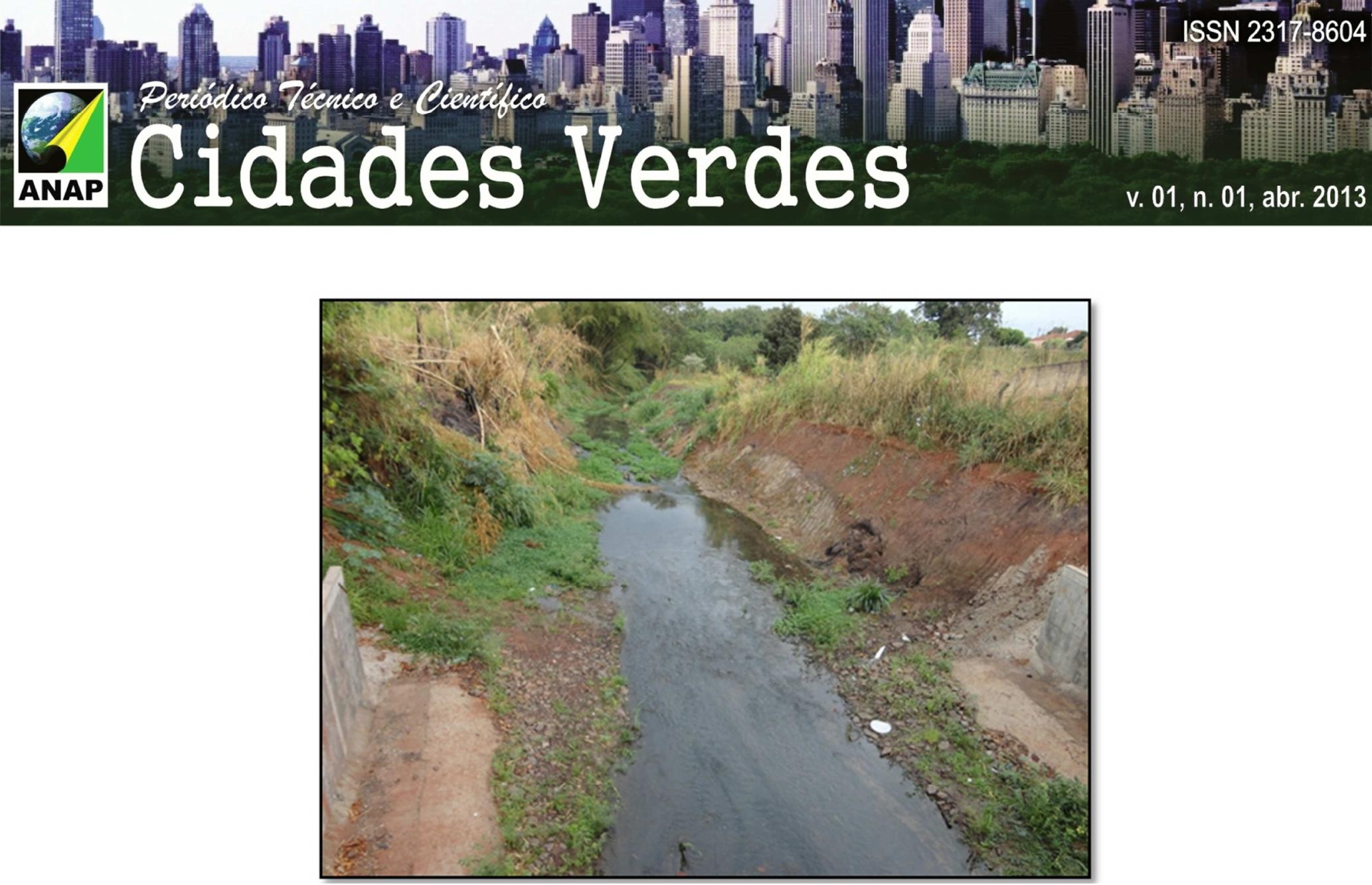

Figura 6. Início da canalização do córrego do Jaboticabal. Acervo pessoal, 2012.

A parte mais urbanizada do córrego do Jaboticabal sofreu obras de impermeabilização do leito, chamada também de canalização. Esse tipo de obra, segundo Tucci, (2003) apud Andrade e Romero, (2005) faz parte de um princípio errôneo de drenagem urbana que visa aumentar a vazão máxima de escoamento em áreas com problemas de inundações. Esse tipo de procedimento apenas altera as áreas que sofrem com as inundações e processos erosivos provocados pela água. Nesse tipo de solução somente se leva em conta um trecho da bacia, não verificando as interferências para 0 seu restante.

\section{Análise do Córrego Cerradinho}

O Córrego Cerradinho (Figura 7) possui características muito diferentes do Jaboticabal quanto à origem e estrutura física e de uso ocupação. Pode-se observar pela Figura 1, que ele é formado pela foz de outros dois córregos, e por este motivo apresenta a maior parte do seu curso no ambiente rural. 

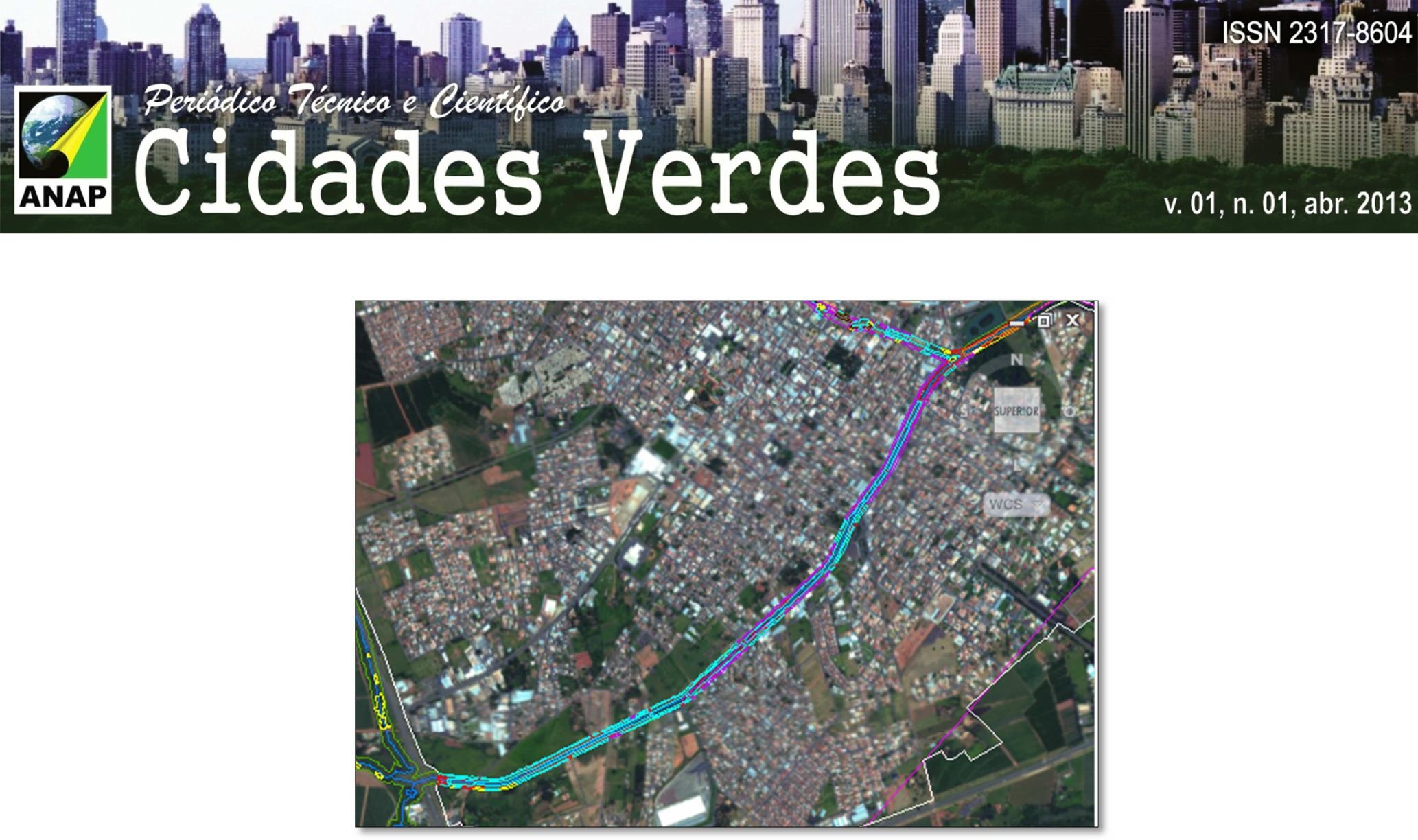

Figura 7: APP vetorizada do Córrego Cerradinho.

O Córrego do Cerradinho, na área urbana localiza-se entre a Avenida Carlos Berchieri e a estrutura da avenida é a ocupação das APPs (Tabela 4).

TABELA 4: Classes de uso da terra mapeadas na imagem do Satélite World View na microbacia hidrográfica do Córrego do Cerradinho.

\begin{tabular}{l|rr}
\hline Classes de uso e ocupação & Área $\left(\boldsymbol{m}^{2}\right)$ & $\%$ \\
\hline Vegetal & & \\
Campo Sujo & $1.534,143$ & 0,7 \\
Áreas Edificadas & $104.926,93$ & 46,0 \\
Área Impermeabilizada & $27.796,52$ & 12,2 \\
\hline Total & $93.800,351$ & 41,1 \\
\hline
\end{tabular}

Como podemos observar, o Córrego do Cerradinho possui uma alta impermeabilização de suas margens pelas vias públicas, calçadas e ruas correspondendo um total de 41,1\%. Ao comparar os dois córregos Jaboticabal e Cerradinho, a diferença entre eles chega a 31,1\%. Esse tipo de ação provoca uma grande perda de infiltração para recarga do lençol freático. Em épocas de alta pluviosidade esses córregos podem vir 


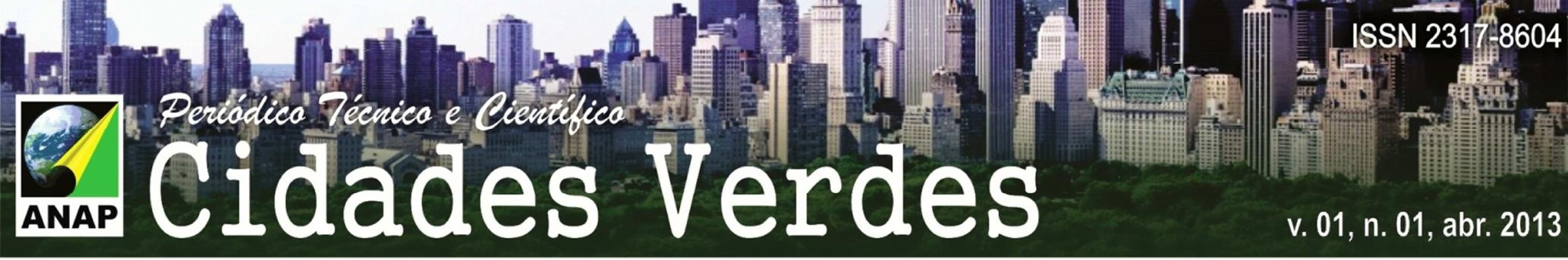

a receber uma alta quantidade de água que quando não são comportadas por sua calha as áreas em volta do córrego podem sofrer com processos de enchentes.

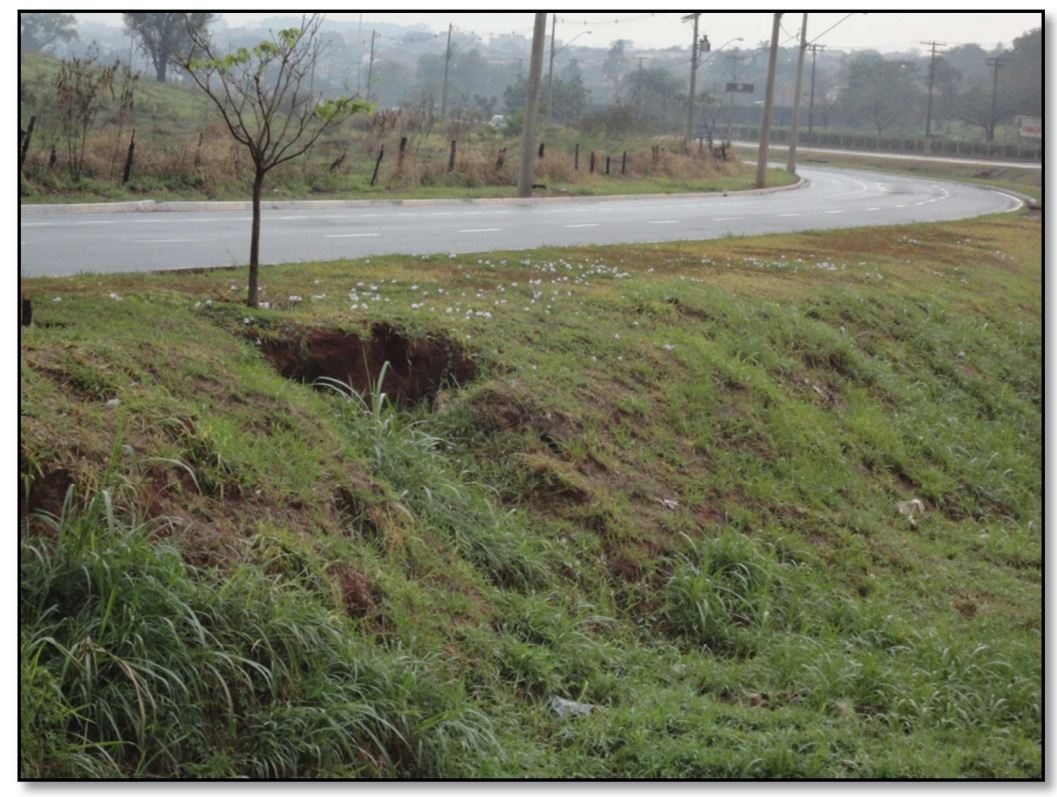

Figura 8: Processo erosivo no Córrego Cerradinho. Acervo pessoal, 2012.

As margens podem sofrer com processos erosivos (Figura 8), principalmente em épocas de chuvas, pois a falta de proteção vegetal nas margens acaba por deixar o solo exposto por ações de erosão dos sedimentos das margens.

\section{Foz dos Córregos Jaboticabal e Cerradinho}

Os dois córregos, Jaboticabal e Cerradinho se encontram dentro do perímetro urbano de Jaboticabal, mais precisamente em frente da Prefeitura. (Figura 9 e 10), formando então sua foz nesse trecho após o seu deságue do Cerradinho; o Córrego continua com o nome de Córrego do Jaboticabal, após sair da cidade o córrego atravessa a área do campus da UNESP de Jaboticabal. 

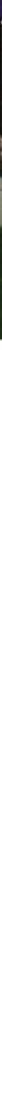

Figura 9: Foz - Córrego Jaboticabal e Cerradinho

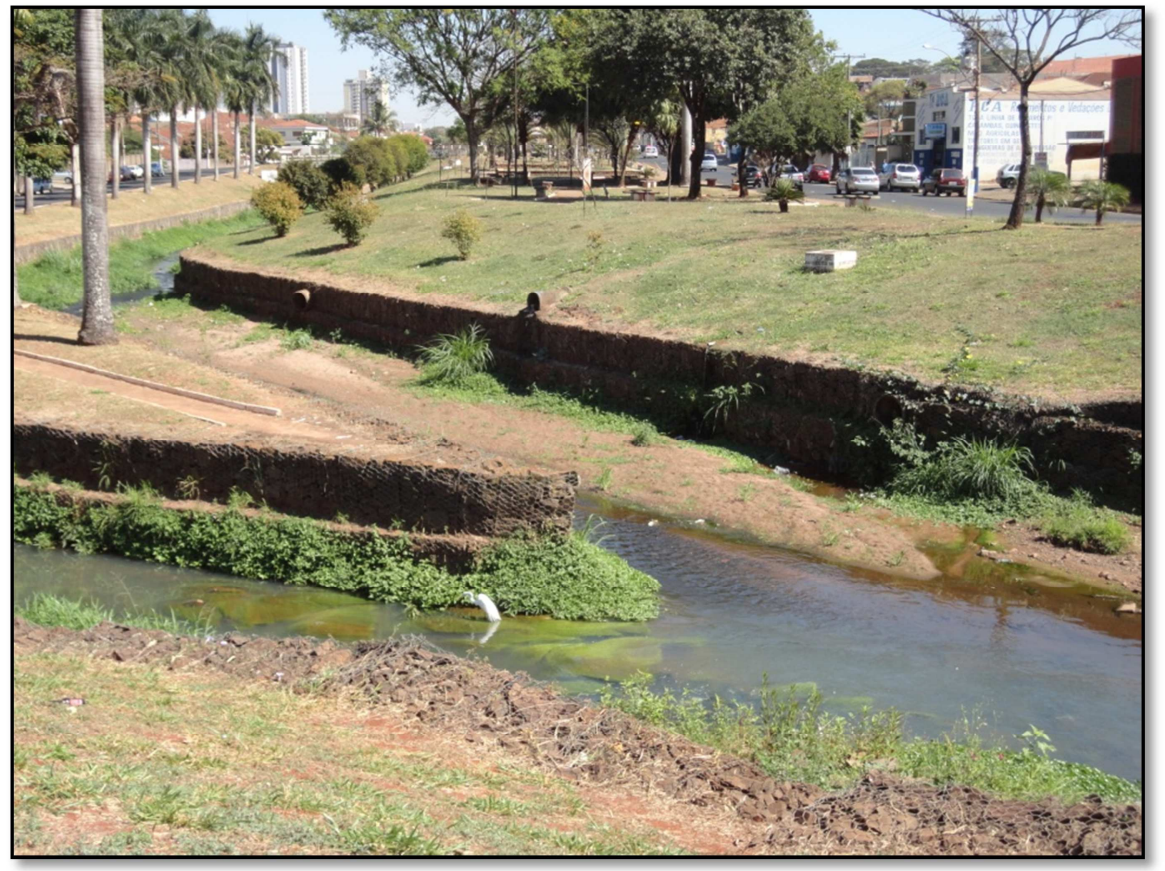

Figura 10: Foz dos Córregos: Cerradinho (Abaixo) e Jaboticabal (Acima). Acervo pessoal, 2012.

Devido à diferença na conformação dos dois córregos, desde sua nascente até chegar a sua foz, suas águas atravessam realidades diferentes; e conforme estudos preliminares sobre a qualidade da água desses córregos, essa junção transmite reflexos 
na qualidade da água que saíra do espaço urbano. Os estudos corroboram com alguns dados apresentados por Borges et al. (2003).

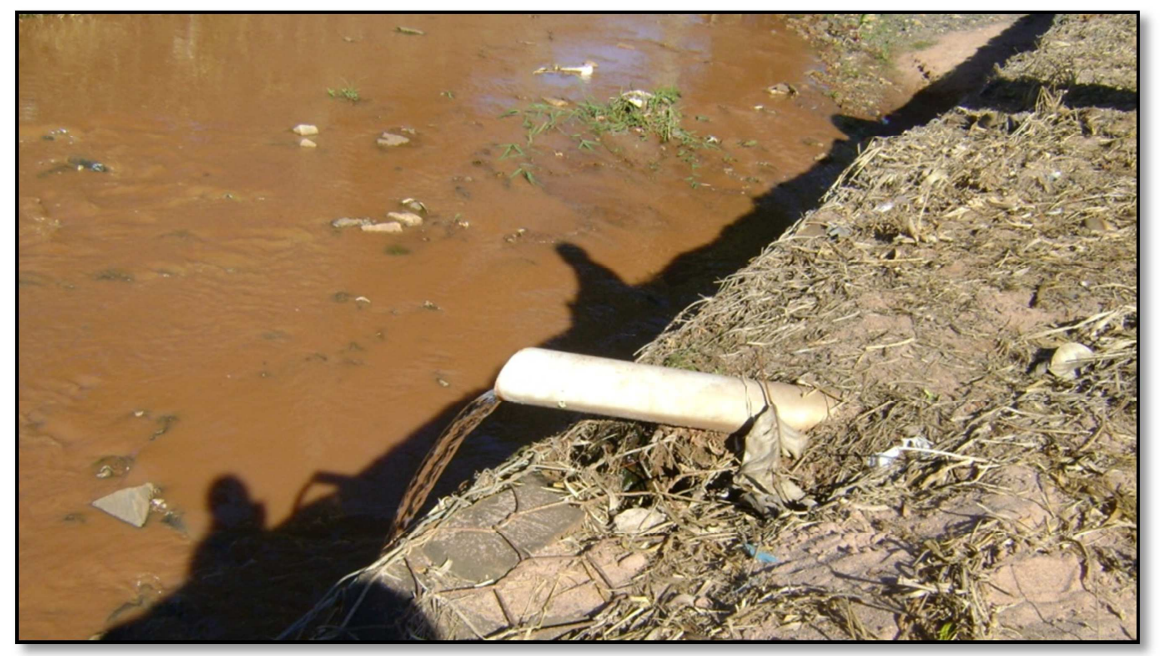

Figura 11. Nascente canalizada próxima à foz do Córrego Jaboticabal. Acervo pessoal, 2010.

Durante as visitas foi localizada uma nascente canalizada (Figura 11). Sua origem não foi localizada, desta forma não foi possível avaliar a influência desse tipo de ação antrópica sobre o curso d'água. Estudos podem ser feitos em busca de avaliar questões sobre vazão e contaminação da água por coliformes buscando verificar o nível de pressão antrópica sofrida por essa nascente, antes de apresentar seu afloramento e junção com o Córrego do Jaboticabal.

TABELA 5: Classes de uso da terra mapeadas na imagem do Satélite World View na microbacia hidrográfica da Foz do Córrego Jaboticabal e Cerradinho.

\begin{tabular}{l|rr}
\hline Classes de uso e ocupação & Área $\left(\boldsymbol{m}^{2}\right)$ & $\%$ \\
\hline Vegetal & $30.780,575$ & 43,39 \\
Campo Sujo & $35.403,386$ & 49,91 \\
Áreas Edificadas & 0 & 0 \\
Área Impermeabilizada & $4.749,646$ & 6,69 \\
\hline Total & $70.931,607$ & 100,0 \\
\hline
\end{tabular}




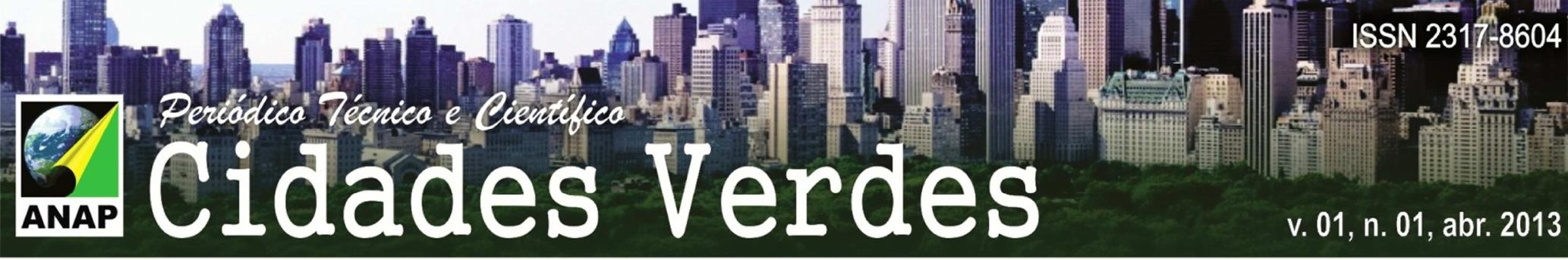

Está é a APP que apresenta a maior porcentagem de área com vegetação, 43,39\%, e não possui edificações. Apresenta pequena parcela impermeabilizada e a área restante $(49,91 \%)$ se apresenta passível de projetos de reflorestamento (Tabela 5).

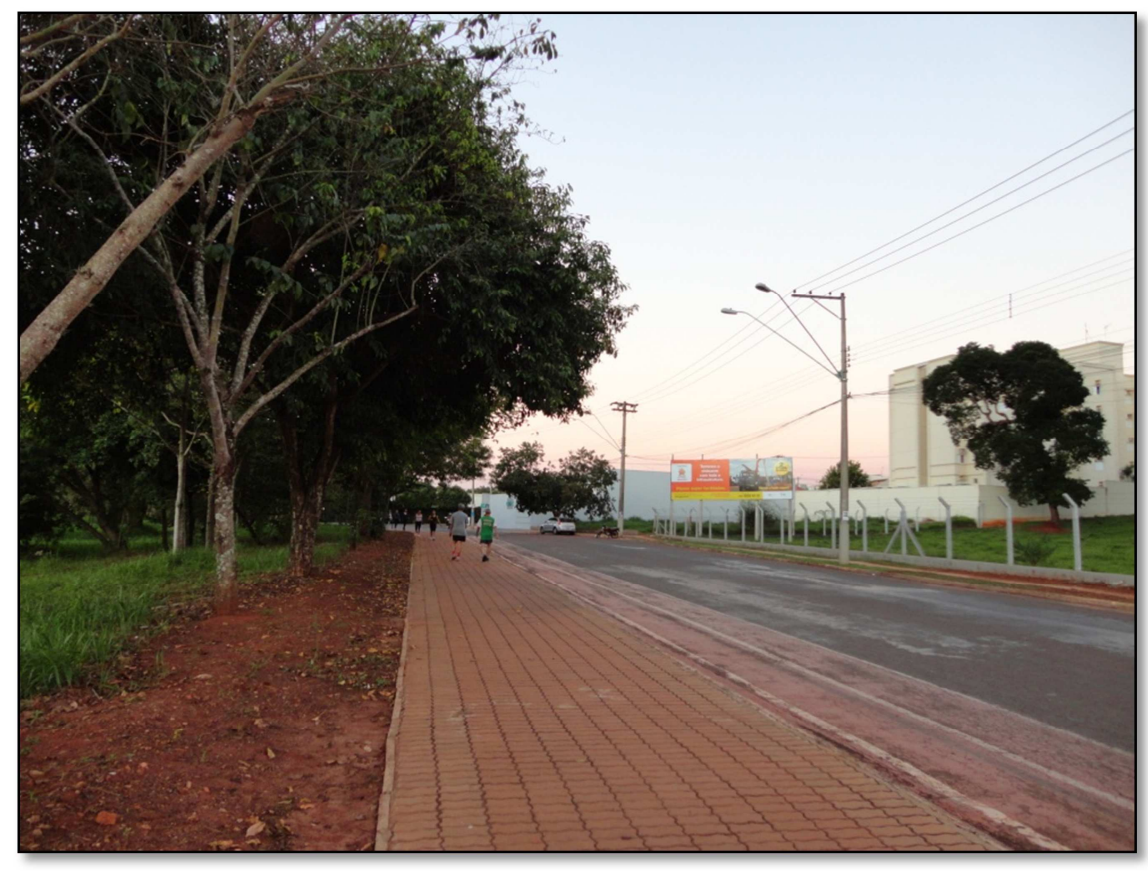

Figura 12: Parque Argeo Roma. Avenida Carlos Berchieri. Acervo pessoal, 2012.

Na foz dos Córregos Jaboticabal e Cerradinho, é encontrada uma APP urbana em forma de Parque Linear urbano (Figura 11). A área de APP foi reflorestada e em 1998 transformada em parque, Parque Argeo Roma. Essa área se tornou um ponto de referência para a prática de atividades físicas após a instalação de calçadas e ciclovia (MELO, et al. 2011).

Os parques lineares surgem de forma a transformar os espaços e fazer com que estes sejam valorizados pela sociedade ao proporcionar uma sadia qualidade de vida em um ambiente ecologicamente equilibrado (OLIVEIRA e BORGES, 2011). De acordo com Andrade e Romero, (2005) quando as APPs são reconhecidas ou fazem parte do conjunto de áreas verdes urbanas são gerados vários ganhos ambientais e sociais. A não impermeabilização do solo e a manutenção da vegetação nativa acabam por gerar um microclima no ambiente urbano no qual ocorre uma mudança na temperatura, 


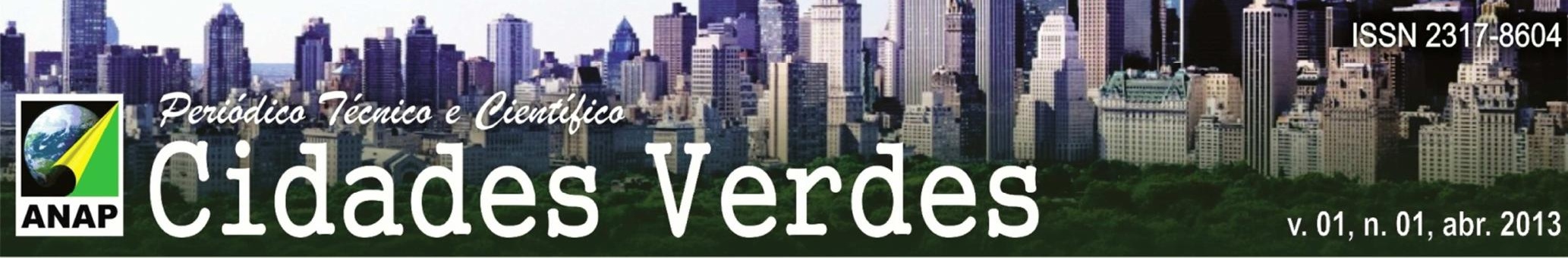

luminosidade, além de proporcionar um papel importante na estabilidade geomorfológica que naturalmente são menos estáveis, além de contribuir para a manutenção da riqueza da fauna e flora local, além de funcionarem como uma área de drenagem natural (ANDRADE e ROMERO, 2005).

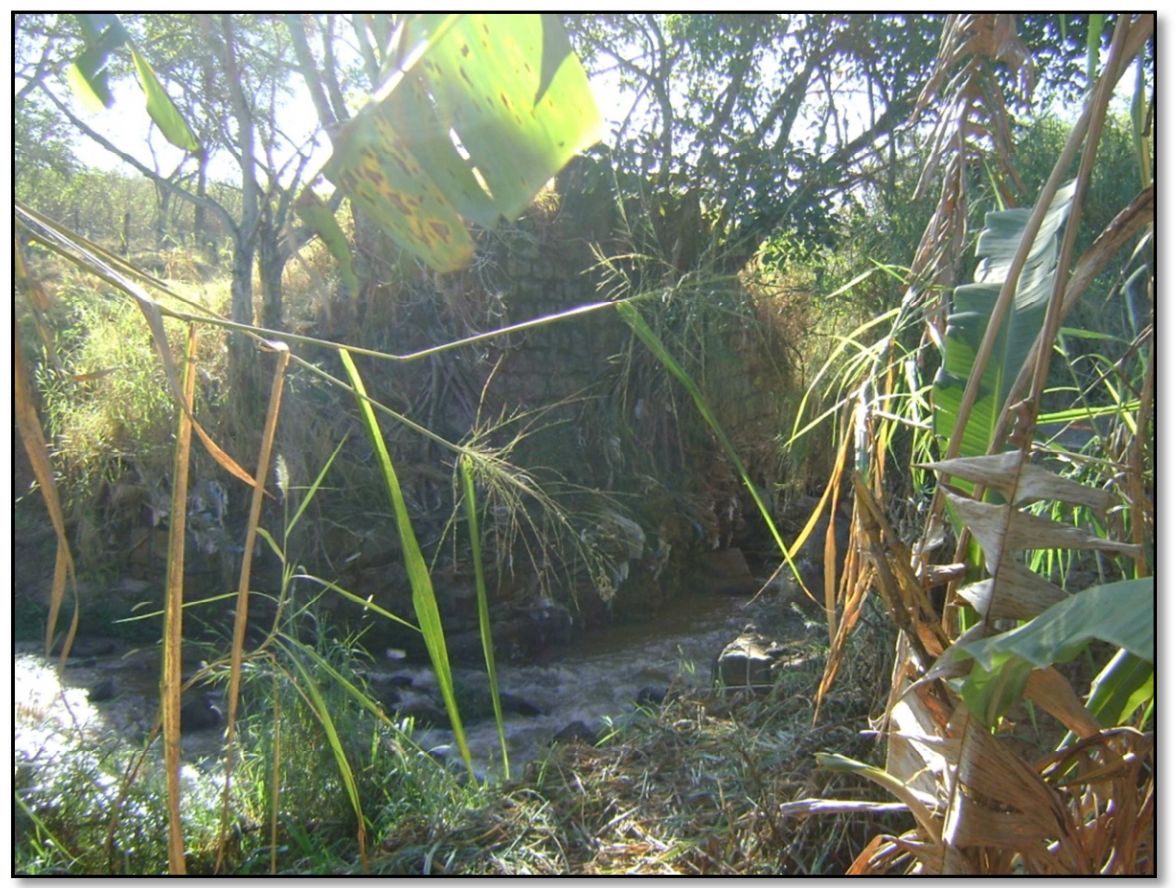

Figura 13: Foz do Córrego do Jaboticabal na área do Parque Argeo Roma. Acervo pessoal, 2012.

Esse tipo de ambiente também pode provocar uma melhora na qualidade da água, pois com a preservação das APP o recurso hídrico fica protegido pela vegetação e não tão a mercê das intervenções antrópicas relacionadas à poluição por resíduos sólidos jogados pela população. Como podemos observar pela Figura 13, o distanciamento do córrego da população pode contribuir para uma melhora da qualidade, pois ainda existe em muitas pessoas a ideia de que o córrego é um dispersor de dejetos humanos. Estudos realizados por Borges, et al. (2003) relatam que o Córrego do Jaboticabal recebeu esgotos até 1999.

Para o reflorestamento em áreas urbanas, os estudos são incipientes. Nesses casos, deve-se alertar os governantes esta necessidade, pois grande parte dessa área não está sendo ocupada com edificações, que causariam algum transtorno, caso fossem 
desocupadas, sendo passiveis de programas de reflorestamento em curto e médio prazo. Em longo prazo, tal problemática cessaria se fosse instituída como lei municipal a aprovação de loteamentos urbanos após delimitação da APP e da reserva legal nessas áreas.

Ainda a norma capitalista dita o mercado, a vida, a sociedade, porém quando se avaliam os prejuízos que podem ocorrer por não preservar o meio ambiente em que vivemos, observa-se a necessidade de recuperação. Enxerga-se o processo de impermeabilização dos leitos dos córregos e o gasto com a reconstrução civil e saúde pública, após grandes enchentes. Assim, os estudos para o planejamento ambiental em áreas urbanas é uma necessidade urgente em conjunto com a educação ambiental para conscientizar a população da necessidade dessas áreas para a cidade sustentável.

Este tipo de trabalho é importante para a determinação de áreas passíveis de reflorestamento e identificar áreas prioritárias para readequação ambiental. O tipo de uso e ocupação do solo realizado nas APP urbanas reflete em muitos problemas enfrentados pela cidade, como enchentes, erosão de encostas, deslizamentos, assoreamento que podem provocar sérios prejuízos diretos e indiretos na população local (MORAES, et al. 2009)

\section{CONCLUSÃO}

A elaboração dos mapas temáticos com a e delimitação do uso e ocupação das APPs, proporcionou um material para servir de base para a elaboração de projetos e outros estudos que visam a gestão ambiental e zoneamento urbano.

A partir desses mapas foi possível analisar o uso do solo nas áreas de preservação permanentes do perímetro urbano.

A identificação de áreas de maior fragilidade ambiental serviu de subsídio à elaboração de diretrizes, sendo parte integrante de estudos da qualidade de água ou riscos de desastres ambientais, como enchentes, deslizamentos e inundações.

\section{Agradecimentos.}


Agradeço ao Conselho Nacional de Desenvolvimento Científico e Tecnológico, CNPq pela bolsa concedida.

\section{REFERÊNCIAS}

AMORIM, L. M. e CORDEIRO, J. S. Como definir critérios para a ocupação de fundos de vale em áreas urbanas. In: Congresso Brasileiro de Engenharia Sanitária e Ambiental, 22. 17p. Joinville, SC. 2003.

ANDRADE, L. M. S.; ROMERO, M. A. B. A importância das áreas ambientalmente protegidas nas cidades. In: Encontro Nacional da Associação Nacional de Pós-Graduação e Pesquisa em Planejamento Urbano e Regional - ANPUR, 9., 2005. Salvador. Anais eletrônicos... Salvador: ANPUR, 2005. Disponível em: < http://vsites.unb.br/fau/pesquisa/sustentabilidade/pesquisadores/Alberto/curr\%EDculo\%20liza/1.pdf>. Acesso em: 13 out. 2011.

AutoCAD 2008®, Autodesk. Educational version, LTI/ DECivil, IS. 1 CD-ROM.

BORGES, M. J. et al. Monitoramento da qualidade Hídrica e Eficiência de Interceptores de Esgoto em Cursos d'Água Urbanos da Bacia Hidrográfica do Córrego do Jaboticabal. RBRH - Revista Brasileira de Recursos Hídricos. v. 8, n. 2. Abr./Jun. 2003., 161 -171. Disponível em:< http://www.abrh.org.br/novo/arquivos/artigos/v8/v8n2/monitoramento.pdf>. Acesso em: 23 set. 2012.

BRASIL, Lei oํ 4.771, de 15 de setembro de 1965, Institui o Código Florestal Brasileiro e dá outras providências. Publicação - Diário Oficial da União, Brasília, DF, 16 set. 1965. Disponível: <http://www.siam.mg.gov.br/sla/download.pdf?idNorma=4409> Acesso em: 5 mar. 2011.

BRASIL. Congresso Nacional. Lei no 9.433, de 8 de jan. de 1997. Institui a Política Nacional de Recursos Hídricos, cria o Sistema Nacional de Gerenciamento de Recursos Hídricos, Diário Oficial da União de 9 jan. 1997. Disponível em:< http://www.planalto.gov.br/ccivil_03/LEIS/I9433.htm>. Acesso em 28 set. 2012.

BRASIL. Congresso Nacional. Lei oㅜ 11.977, de 7 jun. 2009, Dispõe sobre o Programa Minha Casa, Minha Vida - PMCMV e a regularização fundiária de assentamentos localizados em áreas urbanas; e dá outras providências. Conversão da Medida Provisória ํo 459, de 2009. Disponível em:< http://www.planalto.gov.br/ccivil_03/_ato2007-2010/2009/lei/l11977.htm>. Acesso em: 27 set. 2012.

BRASIL. Congresso. Senado. Resolução n 303, de 2002, CONAMA, Art. $3^{\circ}$, Dispõe sobre parâmetros, definições e limites de Áreas de Preservação Permanente. Alterada pela Resolução no 341, de 2003. Diário Oficial [a] República Federativa do Brasil, Brasília, DF, 13 maio de 202. Disponível em:

<http://www.mma.gov.br/port/conama/legiabre.cfm?codlegi=299>. Acesso em: 13 out. 2011.

CEPAGRI - Centro de Pesquisas Meteorológicas e Climáticas Aplicadas à Agricultura Cidade Universitária "Zeferino Vaz" - Campinas/SP. Miranda, M. J. et al. Disponível em: <http://www.cpa.unicamp.br/outrasinformacoes/clima_muni_279.html> Acesso em: 1 ago. 2012.

CRUZ, L.S.B. Diagnóstico Ambiental da Bacia Hidrográfica do Rio Uberaba. Campinas -SP. Tese de doutorado, FEAGRI, UNICAMP, 181 p. 2003.

IBGE. IBGE Cidades. Censo 2010. Disponível em: <http://www.ibge.gov.br/cidadesat/topwindow.htm?1>. Acessado em: 07 ago. 2012. 
IBGE. IBGE Cidades. 2012. Disponível em:

<http://www.ibge.gov.br/cidadesat/painel/painel.php?codmun=352430>. Acessado em: 07 ago. 2012.

MELO, A. G. C. et al. Fragmentos Florestais Urbanos. Revista Científica Eletrônica de Engenharia Florestal. ISSN: 1678-3867. Ano IX - Volume 17 - Número 1 Fev. 2011 - Garça, SP. Disponível em:< http://www.revista.inf.br/florestal/pages/artigos/revef17art05.pdf> Acesso em: 9 jul. 2012.

MORAES, I. C. et al. Expansão urbana e degradação de áreas de proteção permanente em zonas urbanas: o caso do córrego Conduta/ Rio Claro/SP. Anais... Congresso de Meio Ambiente da AUGM, 6. AUGM Ambiente 2009. In: Universidade Federal de São Carlos. São Carlos - SP. out. 2009. Disponível em: <http://www.ambiente-augm.ufscar.br/uploads/A2-130.pdf>. Acesso em: 30 jun. 2012.

NARDINI, R. C. Determinação do conflito de uso e ocupação do solo em áreas de preservação permanente da microbacia do Ribeirão Água - Fria, Bofete (SP), visando a conservação dos recursos hídricos. 2009. 72f. Dissertação (Mestrado em Irrigação e Drenagem). Faculdade de Ciências Agronômicas da Unesp - Câmpus de Botucatu, Botucatu, 2009.

OLIVEIRA, D. A.; BORGES, A. W. Possibilidade de uso sustentável das áreas territoriais especialmente protegidas. OBSERVATORIUM: Revista Eletrônica de Geografia, v.2, n.6, p.120-134, abr. 2011. Disponível em:< http://www.observatorium.ig.ufu.br/pdfs/2edicao/n6/8.pdf> Acesso em: 9 jul. 2012.

PISSARRA, T. C. T. Análise da bacia hidrográfica do Córrego Rico na sub-região de Jaboticabal, SP: comparação entre imagens TM-LANSAT 5 e fotografias aéreas verticais. 2002. 132f. Tese (Doutorado em Conservação e Manejo da Água e do Solo) - Universidade Estadual Paulista, Jaboticabal, 2002.

PISSARRA, T. C. T. et al. Morfometria de microbacias do Córrego Rico, afluente do Rio Mogi-Guaçu, Estado de São Paulo, Brasil. Revista Árvore, v.34, n.4, Viçosa July/Aug. 2010. ISSN 0100-6762.

PREFEITURA MUNICIPAL DE JABOTICABAL, Lei complementar $n^{\circ} 44$, de 29 de dezembro de 2.000 Dispõe sobre a revisão qüinqüenal do Plano Diretor do Município de Jaboticabal, instituído pela Lei Complementar $n^{\circ} 19$, de 08 de julho de 1.994, e dá outras providências. Câmara Municipal de Jaboticabal, sessão, 28 dez. 2000. Jaboticabal, SP. Seção IX, p. 14. Disponível em:

<http://www.rc.unesp.br/igce/ceurb/basededados/legislacao\%20das\%20cidades/jaboticabal/leiplanodiretor.p df> Acesso em: 20 jul. 2010.

ROCHA, J.S.M.; KURTS, S.M.J.M. Manual de manejo integrado de bacias hidrográficas. 4 ed. Santa Maria: UFSM/CCR, 2001. 120p.

SANTOS, R. S. Fatores associados à ocorrência de formas imaturas de Aedes aegypti na llha do Governador, Rio de Janeiro, Brasil. Revista da Sociedade Brasileira de Medicina Tropica. Rev. Soc. Bras. Med. Trop. vol.32 n.4 Uberaba July/Aug. 1999. Print version ISSN 0037-8682 Disponível em: <http://www.scielo.br/scielo.php?pid=S0037-86821999000400007\&script=sci_arttext>. Acesso em: 27 set. 2012.

SMA, Secretária do Meio Ambiente. Municípios Verdes Azuis. Critérios para 2008. Disponível em: <http://www.ambiente.sp.gov.br/municipioverdeazul/criterios_2008. pdf>. Acesso em: 28 set. 2012.

TUCCI, C. E. M. Águas urbanas. Estudos avançados. v. 22, n. 63. p. 97-112. 2008. Disponível em:<http://www.scielo.br/pdf/ea/v22n63/v22n63a07.pdf>. Acesso em: 23 set. 2012.

WORLD VIEW: imagem de satélite. Jaboticabal: Prefeitura Municipal de Jaboticabal, 2010. 1 fotografia aérea. 22573×16473. Escala: 1:30. 